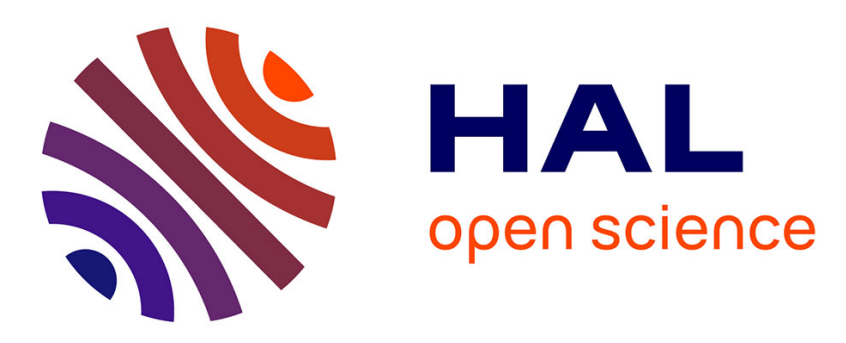

\title{
The second-harmonic generation in chalcogenide glass-ceramic doped with CdS nanocrystals
}

Bai Xue, Bo Fan, Xianghua Zhang, Y. Quiquempois, Gilbert Martinelli, Laurent Calvez

\section{- To cite this version:}

Bai Xue, Bo Fan, Xianghua Zhang, Y. Quiquempois, Gilbert Martinelli, et al.. The second-harmonic generation in chalcogenide glass-ceramic doped with CdS nanocrystals. Materials Letters, 2014, 132, pp.130-133. 10.1016/j.matlet.2014.05.200 . hal-01058360

\section{HAL Id: hal-01058360 https://hal.science/hal-01058360}

Submitted on 8 Oct 2014

HAL is a multi-disciplinary open access archive for the deposit and dissemination of scientific research documents, whether they are published or not. The documents may come from teaching and research institutions in France or abroad, or from public or private research centers.
L'archive ouverte pluridisciplinaire HAL, est destinée au dépôt et à la diffusion de documents scientifiques de niveau recherche, publiés ou non, émanant des établissements d'enseignement et de recherche français ou étrangers, des laboratoires publics ou privés. 


\title{
Second-harmonic generation in chalcogenide glass-ceramic doped
}

\section{with CdS nanocrystals}

Bai Xue ${ }^{1}$, Bo Fan ${ }^{1}$, Xianghua Zhang ${ }^{1}$, Yves Quiquempois ${ }^{2}$, Gilbert Martinelli ${ }^{2}$, Laurent

$$
\text { Calvez*1 }
$$

${ }^{1}$ Equipe Verres et Céramiques, Institut des Sciences Chimiques de Rennes, Université Rennes 1, 35042 Rennes Cedex, France

${ }^{2}$ Laboratoire de Physique des Lasers Atomes et Molécules, Université Lille 1, 59655 Villeneuve d'Ascq, France *Corresponding author

E-mail : laurent.calvez@univ-rennes1.fr

Keywords: Optical materials and properties, Amorphous materials, Nanocrystalline materials, Sintering

\begin{abstract}
An innovative way is proposed here to synthesize chalcogenide glass-ceramic by hotpressing a combination of $\mathrm{Ge}_{20} \mathrm{Sb}_{12} \mathrm{~S}_{68}$ glassy powder and non linear CdS nano-particles. The cadmium sulfide nano-particles, which possess second-harmonic generation property, were synthesized from basic cadmium solution strongly complexed by amine. The obtained glassceramics present homogeneous distribution of the crystals. The transmission reaches $30 \%$ at 5 $\mu \mathrm{m}$ and up to $60 \%$ at $10.6 \mu \mathrm{m}$. Second-harmonic generation at $0.9 \mu \mathrm{m}$ has been detected. This technique can overcome the uncontrollable hetero-crystallization which tends to occur in the glass-ceramics prepared by the conventional thermal treatment method.
\end{abstract}




\section{Introduction}

Chalcogenide glasses are usually polarized by various manners to generate SHG $[1,2]$. The generated susceptibility $\chi^{(2)}$ does not remain constant and decays over time. However, thermal treatment [3] is another route to obtain permanent SHG due to the presence of nonlinear crystallites within glassy matrix.

CdS crystal owns a large second-order optical non-linear coefficient $(+44 \pm 12.6 \mathrm{pm} / \mathrm{V}$ at $1.064 \mu \mathrm{m})[4,5]$. Chalcogenide glass $\mathrm{GeS}_{2}-\mathrm{Ga}_{2} \mathrm{~S}_{3}-\mathrm{CdS}[6]$ was studied to induce permanent second-order non-linearity in glass-ceramics containing $\mathrm{CdGa}_{2} \mathrm{~S}_{4}$ crystallites with a $\chi^{(2)}$ estimated to be $38.85 \mathrm{pm} / \mathrm{V}$ [6]. But the second-order optical non-linear coefficient is only generated from a crystallized surface layer of about $15 \mu \mathrm{m}$ which is difficult to control and induce strong scattering losses. Another study concerning the addition of metallic cadmium in the $\mathrm{Ge}_{25} \mathrm{Sb}_{10} \mathrm{~S}_{65}$ [7] base glass to generate non-centro-symmetric CdS micro-crystals indicates that the $\mathrm{Cd}_{4} \mathrm{GeS}_{6}$ phase is preferentially instead of $\mathrm{CdS}$ by using thermal treatment. So far, no publications have reported glass-ceramic with permanent SHG signals only caused by the presence of non-linear crystals homogeneously dispersed. Since CdS crystals are difficult to make by conventional thermal annealing, new techniques are required to synthesize glassceramics with unique CdS crystals homogeneously dispersed in the matrix.

In this report, a new way to synthesize chalcogenide glass-ceramics is put forward, focused on chalcogenide glass-ceramic presenting second-order non-linear susceptibility attributed to the doping of $\mathrm{CdS}$ nanoparticles. Moreover a specific glass composition (Ge-SbS) possessing a wide transparency range and a close refractive index to that of CdS has been chosen to limit the scatterings and optical losses. Glassy powder and CdS powder were thoroughly mixed using a planetary miller and sintered by hot-pressing under vacuum. Second-order non-linear signals can be detected upon these glass-ceramics. 


\section{Experimental}

\section{Characterization:}

Differential Scanning Calorimeter (DSC TA Q20) was used to determine the characteristic temperatures. Morphology images were recorded by Scanning Electronic Microscope. Crystal structure of the pellets was characterized using a Panalytical X'PERT Powder diffractometer operating with $\mathrm{Cu} \mathrm{K} \alpha$ radiation. Transmission spectra were recorded by a double-beam spectrophotometer Perkin Elmer Lambda 1050 UV/VIS/NIR URA and by a Bruker Vector 22 spectrophotometer in the mid-infrared region. The second-harmonic generation at $0.9 \mu \mathrm{m}$ was carried out by a Maker fringe method using an optical parametric oscillator (OPO, $\lambda=1.8 \mu \mathrm{m}$ ) as the light source. Detailed information of the measurement was described in previous reports [7].

Synthesis of CdS powder:

CdS powder was synthesized from basic cadmium solution strongly complexed by amine [8]. The formula of the reaction is as follow:

$$
\mathrm{Cd}^{2+}+\mathrm{CH}_{3} \mathrm{CSNH}_{2}+\mathrm{H}_{2} \mathrm{O} \rightarrow \mathrm{CdS} \downarrow+\mathrm{CH}_{3} \mathrm{C}(\mathrm{O}) \mathrm{NH}_{2}+2 \mathrm{H}^{+}
$$

CdS was synthesized in a 500-ml beaker and be stirred at room temperature by magnetic stirring to obtain crystals of homogenous size. The solution was prepared from the solutions to be $0.5 \mathrm{~mol} / \mathrm{L}$ in $\mathrm{CH}_{3} \mathrm{CSNH}_{2}, 1 \mathrm{~mol} / \mathrm{L}$ in $\mathrm{NH}_{4} \mathrm{Cl}$, and $0.1 \mathrm{~mol} / \mathrm{L}$ in $\mathrm{CdCl}_{2}$. The $\mathrm{pH}$ was adjusted around 9.5 [9]. After 40-hours reaction, the turbid liquid was centrifuged to precipitate rapidly, that could prevent the aggregation during long time aging. At last, the precipitates were washed with deionization water and ethanol.

Glass synthesis:

The glassy matrix $\mathrm{Ge}_{20} \mathrm{Sb}_{12} \mathrm{~S}_{68}$ has been chosen as it presents a moderate glass transition temperature $\left(270^{\circ} \mathrm{C}\right)$, a low band-gap of $550 \mathrm{~nm}$ and a refractive index of 2.28 (2.35 for CdS). The glass was synthesized by conventional melt-quenching method. High purity raw elements 
$\mathrm{Ge}(5 \mathrm{~N}), \mathrm{Sb}(5 \mathrm{~N})$ and $\mathrm{S}$ were used. Sulfur was purified by distillation to remove the residual impurities $(\mathrm{O}-\mathrm{H}, \mathrm{C} \ldots)$. Raw elements were transferred into a 9-mm diameter silica tube, which was sealed under a vacuum $\left(10^{-3} \mathrm{~Pa}\right)$. Then, the tube was heated to $850^{\circ} \mathrm{C}$ and held for about 12 hours before being quenched in water until room temperature. The glass was broken and milled into powder using a planetary grinder (PM100 from Retsch) in a glove box under argon to avoid air pollution.

Preparation of glass-ceramics:

The CdS powder (10 mass\%) was mixed with the $\mathrm{Ge}_{20} \mathrm{Sb}_{12} \mathrm{~S}_{68}$ glassy powder (90 mass\%) in ethanol and stirred to well homogenize the mixture. The mixture was stirred until the ethanol was fully evaporated and then dried in an oven at $70^{\circ} \mathrm{C}$ for 12 hours to volatilize the residual ethanol.

The mixture was sintered by hot-pressing (HP) with a home-made equipment [10]. A stainless steel mold with an inner diameter of 20 -mm was used. The hot-pressing at $T_{g}+100^{\circ} \mathrm{C}$ was performed under a primary vacuum using a load of $31 \mathrm{MPa}$. The procedure lasted for various durations. Then the sample was slowly cooled down to room temperature to relax the inner constrains.

In parallel, one sample was synthesized by re-melting the entire mixture in a sealed silica tube under vacuum at $750^{\circ} \mathrm{C}$ for 5 hours to test the possibility to prepare controllable glass-ceramic by the usual melt-quenching process.

\section{Results and discussion}

Two samples were sintered by HP using the sintering parameters listed in Table 1 . The sample made in silica tube is denoted as CD3. To well detect the signals, glass-ceramic slices were then polished to reach a thickness of $0.5-0.7 \mathrm{~mm}$.

XRD patterns of the initial powder and glass-ceramics are shown in Fig.1. Synthesis made at high temperature by sintering (CD2) or by melting (CD3) can lead to a reaction 
between the glassy matrix and CdS crystals which results in the formation of another crystalline phase $\mathrm{Cd}_{4} \mathrm{GeS}_{6}$ [7]. However, the pure CdS phase can still be found in sample CD1 sintered at a lower temperature.

As shown in Fig.2, samples CD1 and CD2 are black instead of red. Even if the sample CD3 is red colored, it is not transparent for the naked eyes due to strong light scatterings. Moreover, strong impurity absorption peaks, such as $\mathrm{O}-\mathrm{H}, \mathrm{S}-\mathrm{H}$ and $\mathrm{H}_{2} \mathrm{O}$, are present in all samples. These impurities directly come from non-purified $\mathrm{CdS}$ under $\mathrm{H}_{2} \mathrm{~S}$ flow and the use of ethanol which helped to homogeneously mix the CdS crystals with the glassy powder.

As observable in Fig.2, optical signals before $1 \mu \mathrm{m}$ can be partially detected through CD1 and CD2 samples. These scatterings could be attributed to the defects (e.g. the pores) and to CdS particles in the samples shown in Fig.3 (a) and (b). Lower sintering temperature induces residual porosity which strongly affects the transmittance even with longer duration. Moreover the use of a reducing atmosphere (vacuum) can strongly impact the behavior of sulfur within the glassy matrix potentially leading to the dark coloration of the samples. Fig.3 (a) presents the interface between the glassy matrix and the crystals. Fig.3 (b) shows that the glass does not fill in perfectly the crystals aggregate. In fact, among the crystals, pores can be seen, demonstrating that a temperature of $380^{\circ} \mathrm{C}$ is not sufficient to make the viscous glass flows all around the crystals. Different refractive index at the interfaces between holes/crystals/glassy matrix can also causes strong scatterings at short wavelength.

As observed in Fig.3 (c) and (d), a higher temperature of sintering used for CD2 enhances the densification of the material, reducing the scatterings by lowering the residual porosity. However higher sintering temperature leads to the formation of heterogeneous $\mathrm{CdS}$ and $\mathrm{Cd}_{4} \mathrm{GeS}_{6}$ crystals in the matrix (see Fig.1). Even with a better densification, the uncontrolled growth of crystals leads CD2 sample to be less transparent than CD1 as shown in Fig.2. 
SHG signal of the $1.8-\mu \mathrm{m}$ incident light can be observed in all samples as shown by the Maker fringe patterns (Fig.4.(A)). The shape of the curves attests the random generation of second harmonic pattern with a typical center plate and a signal decrease at large angles due to Fresnel losses. Moreover, the non-linear shape can be affected by the strong absorption bands due to impurities of water and oxygen. To compare the relative intensity, Maker frange patterns of the quartz and CD3 samples are presented in Fig.4 (B). It is important to note that their intensities are not in the same order of magnitude.

For the moment, the transmittance at $0.9 \mu \mathrm{m}$ is so low that almost $90 \%$ of the signal is absorbed which makes an absolute estimation of the real susceptibility very difficult. Improvement of the transmission at short wavelength or even at mid IR range by improving the sintering process will be necessary to make more efficient the generation of non-linear signals. Nevertheless, this innovative way of making glass-ceramics appears as a very interesting ways to prepare non conventional glass-ceramics. New challenges have to be overcome to enhance their transmittance both in visible and mid-IR ranges.

\section{Conclusions}

In this paper, we proposed a new way to synthesize efficient glass-ceramic by sintering the chalcogenide glassy powder doped with CdS nano-particles. Glassy powder and CdS nano-particles were thoroughly mixed and sintered by HP into a disc. The obtained slices present a pretty low transmission in the mid-IR $(30 \%$ around $5 \mu \mathrm{m})$ and a relatively high transmission of $60 \%$ at $10.6 \mu \mathrm{m}$. SHG signals have been detected in these samples. Even if the optical results are not at the height of our expectation, the feasibility of this novel technique has been determinate and can be considered as a potential approach to synthesize novel glass-ceramic with specific properties. 


\section{References}

[1] M. Guignard, V. Nazabal, F. Smektala, H. Zeghlache, A. Kudlinski, Y. Quiquempois, G. Martinelli, Optics Express, 2006. 14(4):1524-1532.

[2] Y.Takahashi, Y.Benino, T.Fujiwara, T.Komatsu, Journal of Applied Physics, 2004. 95(7):3503.

[3] C.G.Lin, H.Z.Tao, X.L.Zheng, R.K.Pan, H.C.Zang, and X.J.Zhao, Optics Letters, 2009. 34(4):437.

[4] Marvin J. Weber, Ph.D., Handbook of Optical Materials. 2003: CRC Press.

[5] R.C.Miller, D.A.Kleinman, A.Savage, Phys. Rev. Lett., 1963. 11(4):146.

[6] S. X. Gu, H. P. Hu, H. T. Guo, H. Z. Tao, Optics Communications, 2008. 281:26512655.

[7] M.Guignard, V.Nazabal, X.H. Zhang, F.Smektala, A.Moréac, S.Pechev, H.Zeghlache, A.Kudlinski, G.Martinelli, Y.Quiquempois, Optical Materials, 2007. 30:338-345.

[8] X. Y. Tao, X. B. Zhang, J. P. Cheng, W. Z. Huang, Materials Letters, 2005. 59:26892692.

[9] P. C. Rieke, S. B. Bentjen, Chem. Mater., 1993. 5:43-53.

[10] Elena Petracovschi, Mathieu Hubert, Jean-Luc Adam, Xiang-Hua Zhang, Laurent Calvez, Physica Status Solidi B, 2013. 1-4. 


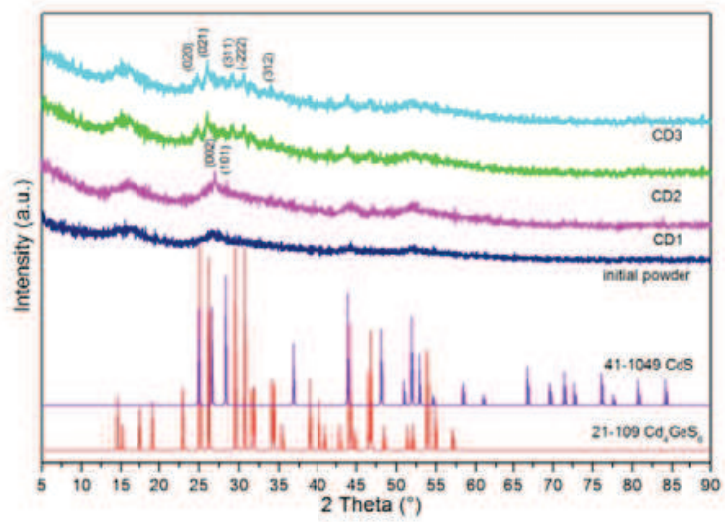

Fig.1. XRD patterns of $\mathrm{CD} 1, \mathrm{CD} 2$ and $\mathrm{CD} 3$ samples compared to the initial mixture powder and PDF card

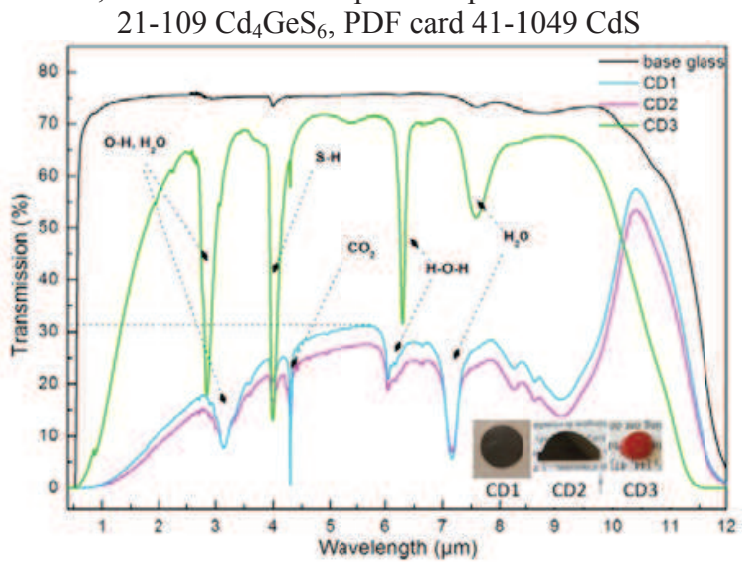

Fig.2. Transmission curves of the slices CD1 and CD2 sintered at $380^{\circ} \mathrm{C}$ and $385^{\circ} \mathrm{C}$ compared to the base glass and the $\mathrm{CD} 3$ synthesized in a silicate tube sealed under vacuum and heated at $750^{\circ} \mathrm{C}$; inset photo presents

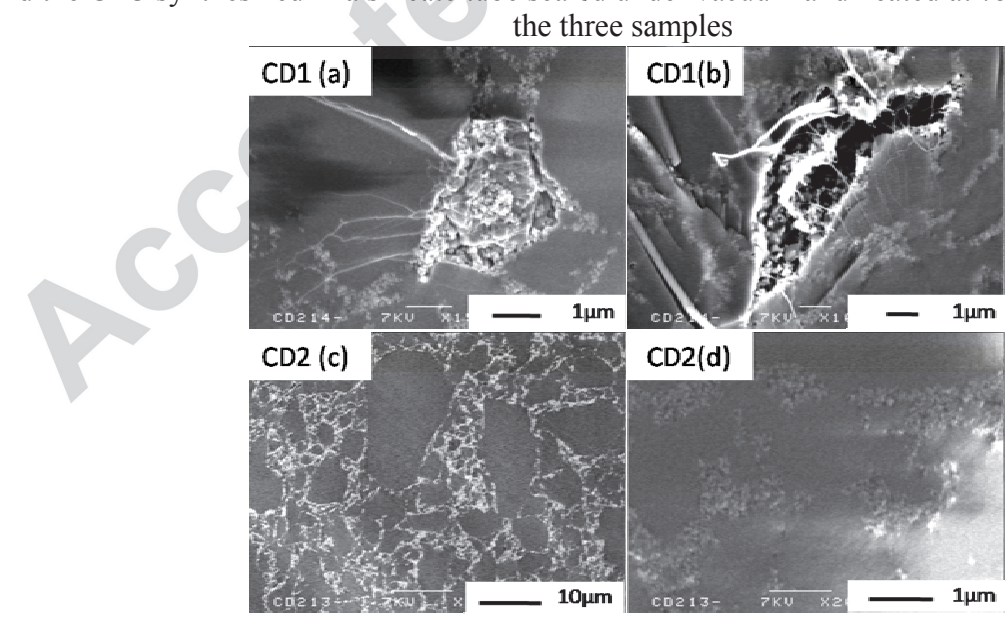

Fig.3. SEM photos of CD1 and CD2 slices. Observation of not well sintered pellets (CD1), the white points are CdS crystals, the black region seen in (b) is the hole while the other grey region is glass; and well sintered pellets (CD2), the white points can be seen clearly are CdS crystals while the grey region is glass 


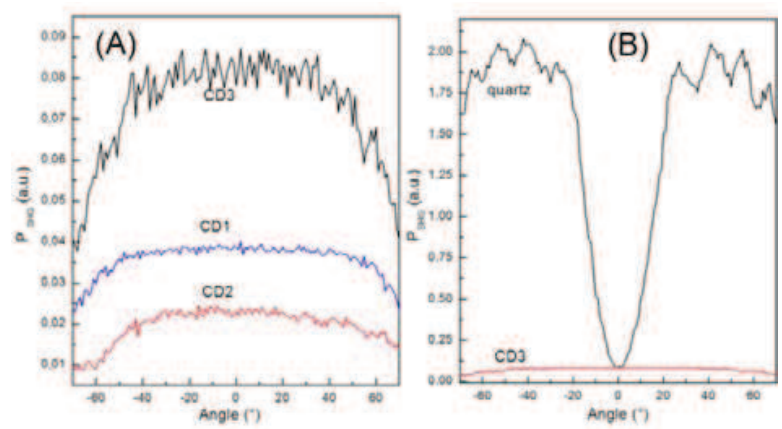

Fig.4. Maker frange patterns of the samples CD1, CD2 and CD3 (A); Maker frange patterns of the sample CD3 compared with quartz (B)

Table 1. Sintering parameters of the samples made by HP

\begin{tabular}{ccccccc}
\hline Name & $\mathrm{T}\left({ }^{\circ} \mathrm{C}\right)$ & Press (Mpa) & Time $(\mathrm{min})$ & Liner & Thickness $(\mathrm{mm})$ & Density $\left(\mathrm{g} / \mathrm{cm}^{3}\right)$ \\
\hline $\mathrm{CD} 1$ & 380 & 31 & 420 & $\mathrm{BN}$ & 0.56 & $3.24 \pm 0.004$ \\
$\mathrm{CD} 2$ & 385 & 31 & 240 & $\mathrm{BN}$ & 0.67 & $3.23 \pm 0.004$ \\
\hline
\end{tabular}

